Research Paper

\title{
The Role of Bone Marrow-Derived Cells during Ectopic Bone Formation of Mouse Femoral Muscle in GFP Mouse Bone Marrow Transplantation Model
}

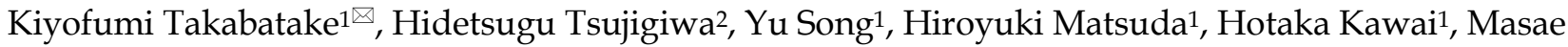
Fujii $^{1}$, Mei Hamada ${ }^{1}$, Keisuke Nakano ${ }^{1}$, Toshiyuki Kawakami ${ }^{3}$, Hitoshi Nagatsuka ${ }^{1}$

1. Department of Oral Pathology and Medicine Graduate School of Medicine, Dentistry and Pharmaceutical Science, Okayama University, Okayama, Japan;

2. Department of life science, Faculty of Science, Okayama University of Science, Okayama, Japan;

3. Hard Tissue Pathology Unit, Matsumoto Dental University Graduate School of Oral Medicine, Shiojiri, Japan.

$\triangle$ Corresponding author: Kiyofumi Takabatake, Department of Oral Pathology and Medicine, Graduate School of Medicine, Dentistry and Pharmaceutical Sciences, Okayama University, 2-5-1 Shikata-Cho, Okayama 700-8558, Japan. Phone: (+81) 86-2351-6651; Fax: (+81) 86-235-6654; E-mail: gmd422094@s.okay ama-u.ac.jp

(c) Ivyspring International Publisher. This is an open access article distributed under the terms of the Creative Commons Attribution (CC BY-NC) license (https://creativecommons.org/licenses/by-nc/4.0/). See http://ivyspring.com/terms for full terms and conditions.

Received: 2017.12.27; Accepted: 2018.04.12; Published: 2018.05.22

\begin{abstract}
Multipotential ability of bone marrow-derived cells has been clarified, and their involvement in repair and maintenance of various tissues has been reported. However, the role of bone marrow-derived cells in osteogenesis remains unknown. In the present study, bone marrow-derived cells during ectopic bone formation of mouse femoral muscle were traced using a GFP bone marrow transplantation model. Bone marrow cells from C57BL/6-Tg (CAG-EGFP) mice were transplanted into $\mathrm{C} 57 \mathrm{BL} / 6 \mathrm{~J}$ wild type mice. After transplantation, insoluble bone matrix (IBM) was implanted into mouse muscle. Ectopic bone formation was histologically assessed at postoperative days 7, 14, and 28. Immunohistochemistry for GFP single staining and GFP-osteocalcin double staining was then performed. Bone marrow transplantation successfully replaced hematopoietic cells with GFP-positive donor cells. Immunohistochemical analyses revealed that osteoblasts and osteocytes involved in ectopic bone formation were GFP-negative, whereas osteoclasts and hematopoietic cells involved in bone formation were GFP-positive. These results indicate that bone marrow-derived cells might not differentiate into osteoblasts. Thus, the main role of bone marrow-derived cells in ectopic osteogenesis may not be to induce bone regeneration by differentiation into osteoblasts, but rather to contribute to microenvironment formation for bone formation by differentiating tissue stem cells into osteoblasts.
\end{abstract}

Key words: Bone marrow transplantation, Bone marrow-derived cell, GFP, Ectopic bone formation, Osteoblast, Insoluble bone matrix (IBM)

\section{Introduction}

In the head and neck region, autogenous bone grafting and artificial biomaterials are currently being used to treat bone defects due to trauma, tumor, or surgical invasion. However, bone tissue for autogenous bone grafting is limited, and there is a risk of infection or invasion to donor tissue. Thus, in recent years, treatment for bone defects using undifferentiated mesenchymal stem cells existing in vivo has attracted attention. In particular, among mesenchymal stem cells, bone marrow-derived stem cells are thought to be the major source of stem cells and are particularly attractive as donor cells in regenerative medicine because of their pluripotency. In vivo, bone marrow-derived stem cells have been reported to differentiate into various cells such as tracheal epithelium, intestinal mucosal epithelium, brain neurons, and salivary glands in normal tissues ${ }^{1,2}$. Further, bone marrow-derived cells can be recruited from bone marrow adjacent to wound tissue during the wound healing process ${ }^{3,4}$. Hence, it has 
become clear that bone marrow-derived cells are involved in the maintenance and repair of various organs. In vitro, recent studies have shown the existence of stem cells obtained by long-term culture of adherent cells from bone marrow cells ${ }^{5-7}$, and these cells differentiate into osteoblasts, chondrocytes, and adipocytes ${ }^{8,9}$. As described above, bone marrowderived cells are deeply involved in tissue regeneration, and there are many reports of bone tissue regeneration using these cells ${ }^{10,11}$. However, the dynamics and role of bone marrow cells in vivo have not been fully elucidated.

We reported that bone marrow-derived cells differentiate into various cells such as macrophages or osteoclasts during bone fracture healing by using a GFP bone marrow transplantation model. Bone marrow-derived cells did not differentiate into osteoblasts or chondrocytes, therefore we considered that osteoblasts might originate from multipotent stem cells around tissue ${ }^{12}$. However, in this orthotopic osteogenesis model, it is difficult to clarify the role of bone marrow-derived cells because osteogenyesis already exists locally in the orthotopic model. Therefore, we herein established an ectopic osteogenesis model by using GFP bone transplantation mice and investigated the dynamics and localization of bone marrow-derived cells over time.

\section{Materials and Methods}

\section{Experimental Animals}

Fifty female mice (16 GFP transgenic mice, C57BL/6-Tg [CAG- EGFP] OsbC14-Y01-FM131, and 34 C57BL/ 6 wild type mice) were used. The Animal Experiment Control Committee of Okayama University approved this study (No. 05-006-099).

\section{Bone Marrow Transplantation}

Bone marrow transplantation was carried out as described previously ${ }^{12}$. Bone marrow cells from GFP mice were collected by introducing Dulbecco's Modified Eagle Medium (DMEM) (Invitrogen, Grand Island, NY, USA) into the marrow space. Cells were resuspended in Hanks' Balanced Salt Solution (HBSS) (Invitrogen, Grand Island, NY, USA) at a volume of approximately $1 \times 10^{7}$ cells $/ 0.25 \mathrm{ml}$. Subsequently, 7-week-old female C57BL/6 recipient mice underwent 10 Gy of lethal whole-body irradiation, and resuspended bone marrow cells were injected into the tail vein of recipient mice. The bone marrow in tibial epiphysis was examined by GFP immunohistochemistry (IHC) 4 weeks after transplantation $(\mathrm{G} \rightarrow \mathrm{W}$ mouse). As a control experiment, bone marrow cells from wild type mice were administered into the tail vein of irradiated GFP mice in the same manner as described above ( $\mathrm{W} \rightarrow \mathrm{G}$ mouse) .

\section{Implantation Procedure}

Insoluble bone matrix (IBM) and recombinant human Bone Morphogenetic Protein-2 (rhBMP-2) were used in this experiment in order to induce ectopic bone formation. The detailed production method of IBM has been described previously ${ }^{13}$. $150 \mathrm{mg}$ IBM loaded with $10 \mu \mathrm{g}$ of rhBMP-2 (PeproTech, Rocky Hill, NJ, USA) was implanted into mouse femoral muscle ${ }^{14}$. Mice were euthanized at postoperative days (PODs) 7, 14, and 28 days for histological observation.

\section{Radiological Examination}

Femurs were collected and radiographed in sagittal orientation using soft X-ray (Softex SRO-M50; Soken Co., Ltd., Tokyo, Japan) at the following settings: $40 \mathrm{kV}, 5 \mathrm{~mA}$, and 1-s irradiation.

\section{Histological Examination}

Embedded tissues were fixed in $4 \%$ paraformaldehyde for $12 \mathrm{~h}$ and then decalcified in $10 \%$ EDTA for 3 weeks. Tissue was embedded in paraffin using routine histological preparation and sectioned to 5 - $\mu \mathrm{m}$ thickness. The sections were used for hematoxylin-eosin (HE) staining and IHC.

\section{Immunohistochemistry}

IHC for GFP was carried out as follows. The sections were deparaffinized in a series of xylene for $15 \mathrm{~min}$ and rehydrated in graded ethanol solutions. Endogenous peroxidase activity was blocked by incubating the sections in $0.3 \% \mathrm{H}_{2} \mathrm{O}_{2}$ in methanol for $30 \mathrm{~min}$. Antigen retrieval was achieved by $0.1 \%$ trypsin treatment for $5 \mathrm{~min}$. After incubation with normal serum, the sections were incubated with primary antibodies at $4^{\circ} \mathrm{C}$ overnight. Tagging of primary antibody was achieved by the subsequent application of anti-rabbit IgG (ABC kit; Vector Laboratories, Inc., Burlingame, CA, USA). Immunoreactivity was visualized using diaminobenzidine (DAB) $/ \mathrm{H}_{2} \mathrm{O}_{2}$ solution (Histofine DAB substrate; Nichirei, Tokyo, Japan), and slides were counterstained with Mayer's hematoxylin.

\section{Double-Fluorescent IHC Staining}

Double-fluorescent IHC for GFP and osteocalcin (OC) was performed using a primary antibody to GFP (rabbit IgG, 1:1000 dilution, Abcam, Tokyo, Japan), and anti-OC (mouse IgG, 1:2000 dilution, Takara Bio, Shiga, Japan). The secondary antibodies used are Alexa Flour 488 anti-rabbit IgG (Abcam, Tokyo, Japan) and Alexa Flour 568 anti-mouse IgG (Abcam, Tokyo, Japan). Antibodies were diluted in Can Get Signal ${ }^{\circledR}$ (TOYOBO, Osaka, Japan). After antigen retrieval, sections were treated with Block Ace ${ }^{\circledR}$ (DS 
Pharma Biomedical, Osaka, Japan) for $30 \mathrm{~min}$ at room temperature. Specimens were incubated with primary antibodies at $4^{\circ} \mathrm{C}$ overnight. Then, specimens were incubated with secondary antibody (1:200 dilution) for $1 \mathrm{~h}$ at room temperature. After the reaction, specimens were stained with $1 \mu \mathrm{g} / \mathrm{ml}$ of DAPI (Dojindo Laboratories, Kumamoto, Japan).

\section{Quantification of GFP Staining and Bone Formation Area}

To quantify GFP staining and bone formation area, cell counts and measurement of the bone formation area were performed at three IBM sites: area of contact between IBM and muscle, area of contact between IBM and femur, and the central part of IBM. In each field, GFP-positive cells were counted in five areas chosen from randomly selected regions (200× magnification), and the hard tissue formation area was measured by ImageJ software (NIH, Bethesda, MD, USA) in five areas chosen from randomly selected regions in HE-stained specimens (200× magnification).

\section{Statistical Analysis}

Statistical analysis was performed using one-

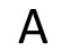

\section{$\mathrm{G} \rightarrow \mathrm{W}$ mouse}
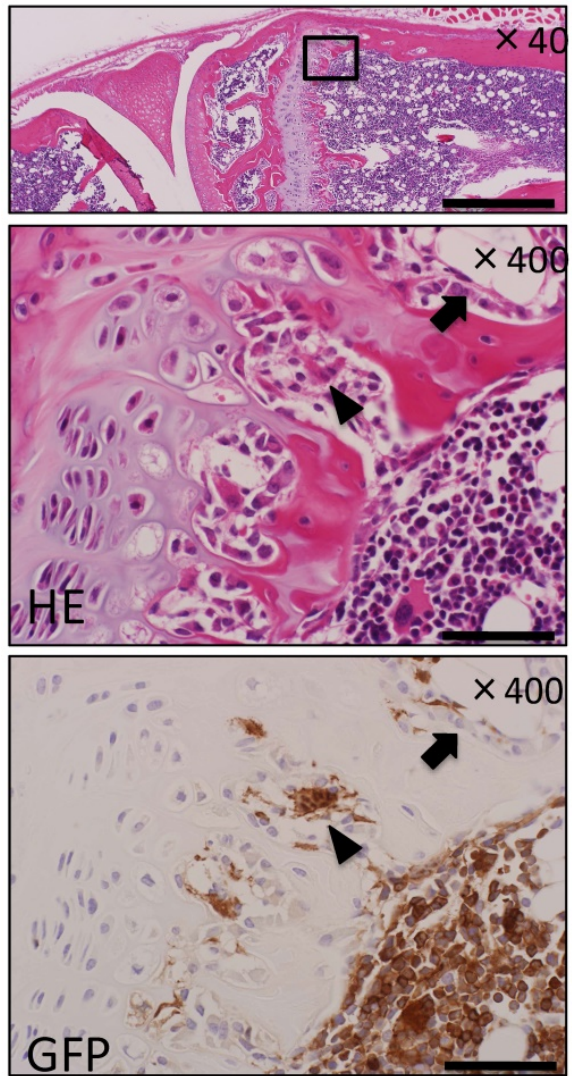

way ANOVA and Fisher's exact tests. A P value $<0.05$ was considered significant. All calculations were made using PASW Statistics 18 (SPSS Inc., Chicago, IL, USA).

\section{Results}

\section{Histological Evaluation of Bone Marrow Transplantation}

The tibial epiphysis of $\mathrm{G} \rightarrow \mathrm{W}$ mice and $\mathrm{W} \rightarrow \mathrm{G}$ mice was examined using HE staining and IHC for GFP. Many donor-derived bone marrow cells were observed among hematopoietic cells constituting bone marrow tissue after bone marrow transplantation in both $\mathrm{G} \rightarrow \mathrm{W}$ mice (Fig. $1 \mathrm{~A}$ ) and $\mathrm{W} \rightarrow \mathrm{G}$ mice (Fig. 1B). This result suggests that donor-derived bone marrow cells successfully replaced hematopoietic cells. In the epiphyseal plate, multinucleated giant cells and osteoclasts were derived from bone marrow cells. Conversely, osteoblasts lining bone tissue were derived from recipient mouse cells, and also adipocytes, and vascular endothelial cells in bone marrow were derived from recipient mouse cells.

B
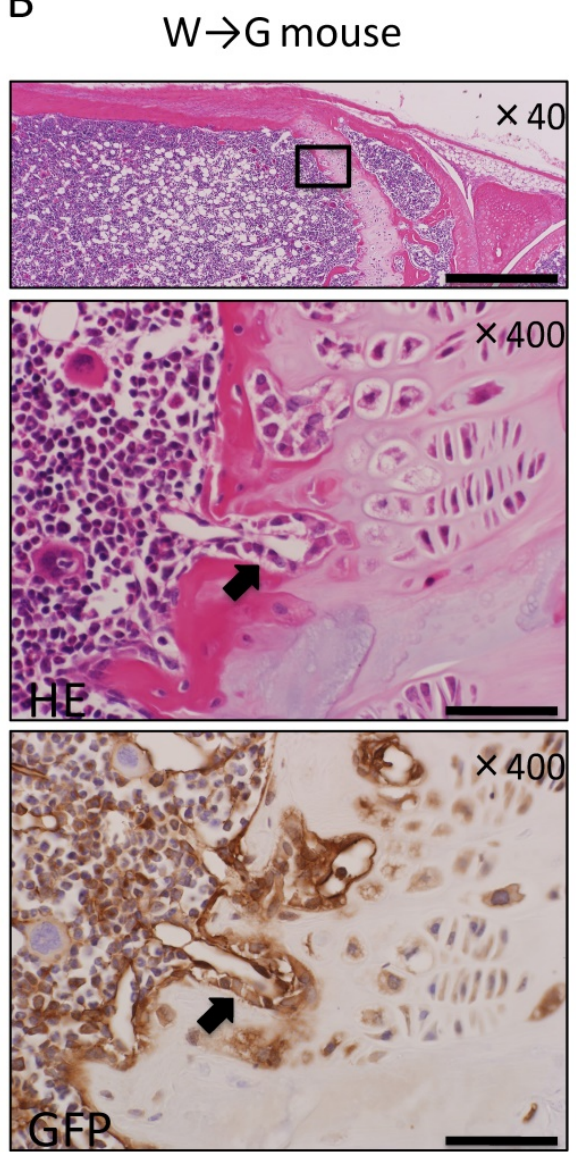

Figure 1. Histological evaluation of bone marrow transplantation by IHC for GFP in the tibial epiphysis. (A) In G $\rightarrow$ W mice, hematopoietic cells in the bone marrow and osteoclasts (arrowheads) were GFP-positive, whereas osteoblasts (arrows) were GFP-negative. (B) In W $\rightarrow$ G mice, osteoblasts (arrows) were GFP-positive, whereas hematopoietic cells were GFP-negative. Scale bars $=500 \mu \mathrm{m}$ in magnification $40 \times$ and scale bars $=50 \mu \mathrm{m}$ in magnification $400 \times$. 


\section{Ectopic Bone Formation in Bone Marrow Transplanted Mice}

In evaluation of ectopic bone formation of soft X-ray, At POD 7, soft X-ray images showed that no radiopaque area was observed around IBM, whereas at POD 14, a delicate radiopaque area was observed around IBM. At POD 28, radiopacity was enhanced and clarified (Fig. 2A). Further, osteogenesis was observed over time in each of the three IBM sites (Fig. 2B).

Histopathological analysis showed cartilage formation around the existing femur and slightly between muscle tissue and IBM at POD 7. In addition, the existing femur demonstrated neonatal bone formation and robust chondrogenesis. Granulation tissue consisting of spindle-shaped fibroblasts was also observed (Fig. 3A). In addition, granulation tissue consisting of spindle-shaped fibroblasts or roundshaped inflammatory cells arose from the existing muscle to IBM, and chondrogenesis partially formed on the muscle side in granulation tissue (Fig. 3B). In immunohistochemical analysis, GFP-positive cells were present among spindle-shaped or round-shaped cells of granulation tissue surrounding formed cartilage. However, GFP-positive cells were not present in formed cartilage tissue (Fig. 3A, B). In the center of IBM, cell migration from surrounding existing tissue was poor, granulation tissue or cartilage tissue formation was not observed, and GFP-positive cells were not present (data not shown).

At POD 14, cartilage and bone formation were observed around the femur and muscle areas. In the femur area, cartilage formed at POD 7 was replaced with neonatal bone, and osteoblasts and osteoclast-like cells were present around neonatal bone (Fig. 4A). Further, in the muscle area, granulation tissue formation was observed between muscle fibers, and bone formation surrounded by osteoblasts was observed in contact with existing muscle tissue (Fig. 4B). Immunohistochemically, osteoblasts on neonatal bone as well as osteocytes were GFP-negative, whereas osteoclast-like cells were GFP-positive (Fig. 4A, B). Few round-shaped inflammatory cells, which were GFP-positive, migrated to the center of IBM (data not shown).

\section{A}

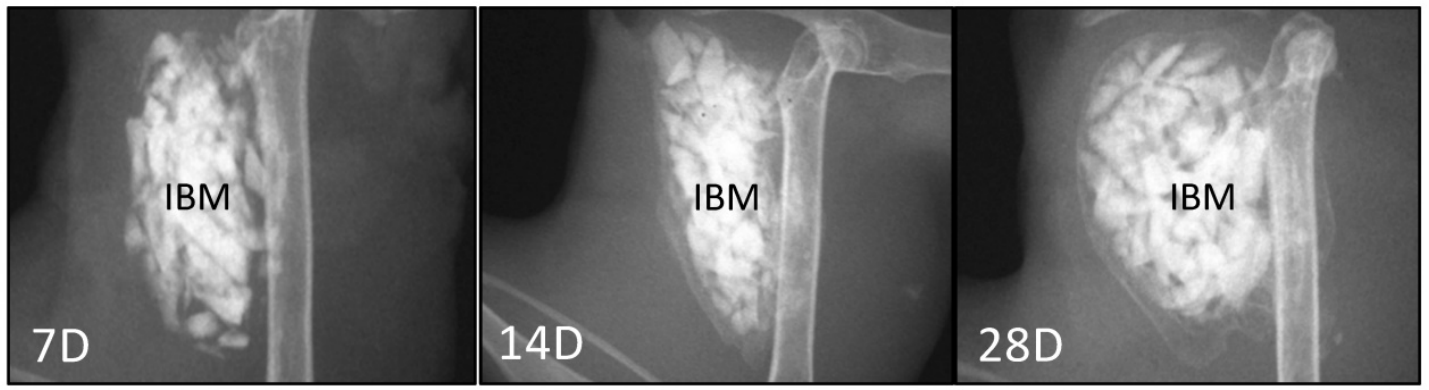

B
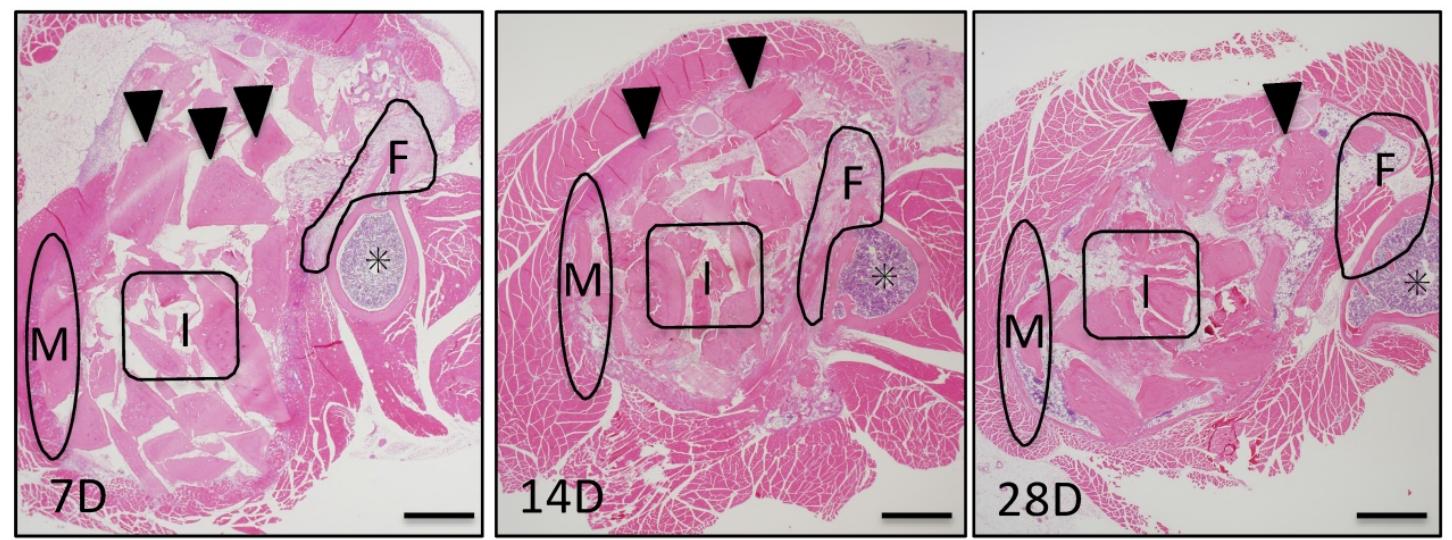

Figure 2. Evaluation of ectopic bone formation. (A) Soft X-ray imaging of IBM at PODs 7, 14, and 28 demonstrated that radiopacity around IBM gradually increased over time. (B) Histological evaluation of ectopic bone formation at three IBM sites (femur area: F, muscle area: M, and IBM: I) over time. Arrowheads represent IBM and asterisks represent bone marrow in the femur. Scale bars $=500 \mu \mathrm{m}$. 

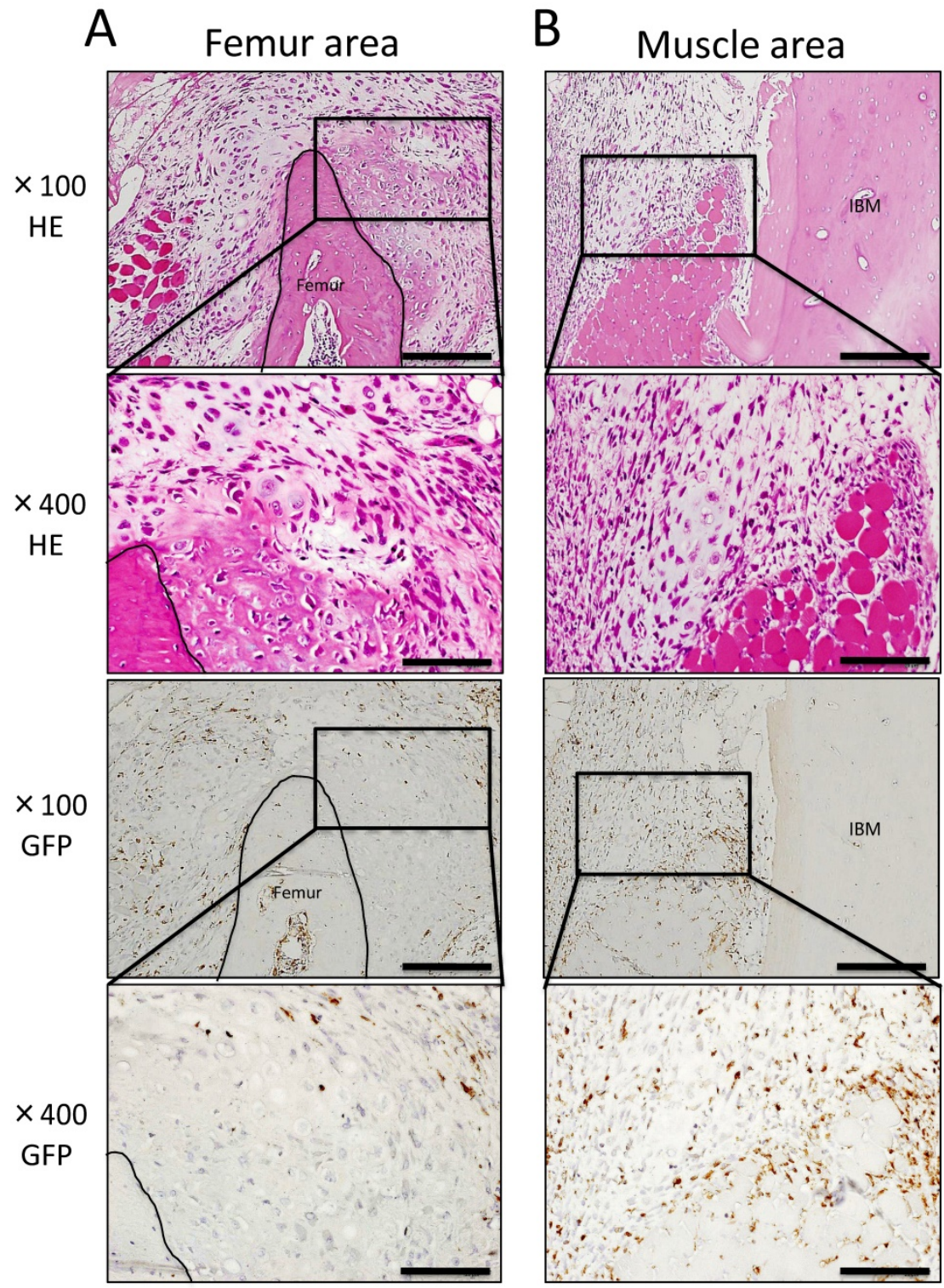

Figure 3. Histological findings at POD 7. (A) Neonatal bone formation and robust chondrogenesis arose from the femur. Granulation tissue consisting of spindle-shaped fibroblasts was observed around new chondrogenesis. (B) Granulation tissue consisting of spindle-shaped fibroblasts or round-shaped inflammatory cells arose from the muscle area, and chondrogenesis was partially observed in granulation tissue. IHC for GFP revealed a large number of GFP-positive cells in granulation tissue around newly formed hard tissue (A, B). Scale bars $=200 \mu \mathrm{m}$ in magnification $100 \times$ and scale bars $=50 \mu \mathrm{m}$ in magnification $400 \times$.

At POD 28, neonatal bone in the femur and muscle areas continued to surround IBM. Further, bone marrow-like tissue was observed inside newly formed bone tissue surrounded by osteoblasts and osteoclast-like cells. In GFP immunostaining of the femur and muscle areas, GFP-positive blood cells of formed bone marrow-like tissue and GFP-positive osteoclasts-like cells surrounding neonatal bone were observed. However, GFP-negative osteoblasts arrayed on the surface of formed bone tissue and GFP-negative osteocytes in neonatal bone were also detected. In the IBM area, bone tissue formation was noted around IBM and bone marrow-like tissue formation occurred with adipocytes and hemocytes present. In addition, GFP-negative cells were present in bone tissue and GFP-positive cells were observed in bone marrow-like tissue (Fig. 5).

\section{Double-Fluorescent IHC for GFP-OC}

Our findings demonstrated that GFP-expressing cells, i.e., bone marrow-derived cells, were not able to differentiate into osteoblasts in ectopic bone formation model mice. Therefore, to investigate in detail whether bone marrow-derived cells have the potential to differentiate into osteoblasts in ectopic bone formation, GFP-OC double-fluorescent IHC was performed at POD 14 when bone formation was most active. In $\mathrm{G} \rightarrow W$ mice, OC-positive osteoblasts were partly observed in neonatal bone and the bone matrix. However, most OC-positive cells were GFP-negative. In connective tissue around neonatal bone, 
GFP-positive / OC-negative spindle-shaped or round-shaped cells were observed (Fig. 6A). Conversely, in $\mathrm{W} \rightarrow \mathrm{G}$ mice, osteoblasts and some areas of neonatal bone matrix were GFP-OC double-positive (Fig. 6B). These findings indicate that bone marrow-derived cells do not differentiate into osteoblasts during ectopic bone formation and osteoblasts are derived from recipient mice.

\section{Correlation between the Number of GFP-Positive Cells and Neonatal Bone Area}

GFP-OC double-fluorescent IHC analysis showed that bone marrow-derived cells were not differentiated into osteoblasts. Therefore, to examine the influence of bone marrow-derived cells on ectopic bone formation, we focused on and analyzed the correlation between the number of GFP-positive cells and the area of formed hard tissue. We counted the number of GFP-positive cells around the existing femur and muscle and in the center of IBM. In addition, the formed hard tissue area including cartilage, bone, and bone marrow-like tissue was measured at the same three IBM sites.

At POD 7, the greatest number of GFP-positive cells was detected around the existing femur and muscle, and the number of GFP-positive cells decreased over time. However, in the center of IBM, the number of GFP-positive cells increased over time (Fig. 7A).
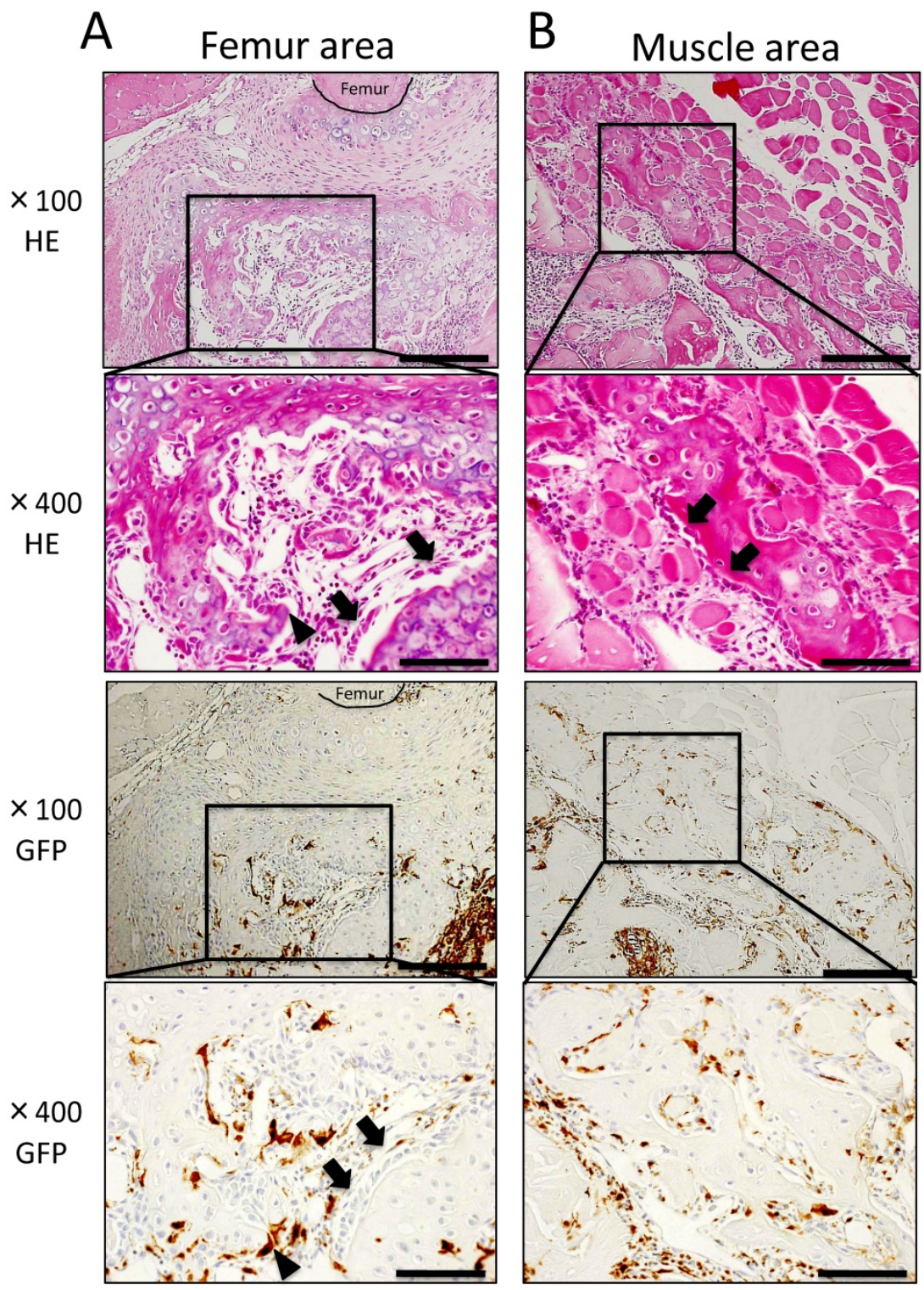

Figure 4. Histological findings at POD 14. (A) In the femur area, robust osteogenesis surrounded by osteoblasts (arrowheads) and osteoclast-like cells (arrows) was observed. Osteoblasts on the neonatal bone as well as osteocytes were GFP-negative, whereas osteoclast-like cells were GFP-positive. (B) In the muscle area, granulation tissue formation was observed between muscle fibers, and bone formation surrounded by osteoblasts (arrowheads) was observed in contact with muscle tissue. Osteoblasts were GFP-negative, whereas osteoclast-like cells, spindle-shaped cells, and round-shaped cells were GFP-positive. Scale bars $=200 \mu m$ in magnification $100 \times$ and scale bars $=50 \mu \mathrm{m}$ in magnification $400 \times$. 
Femur area
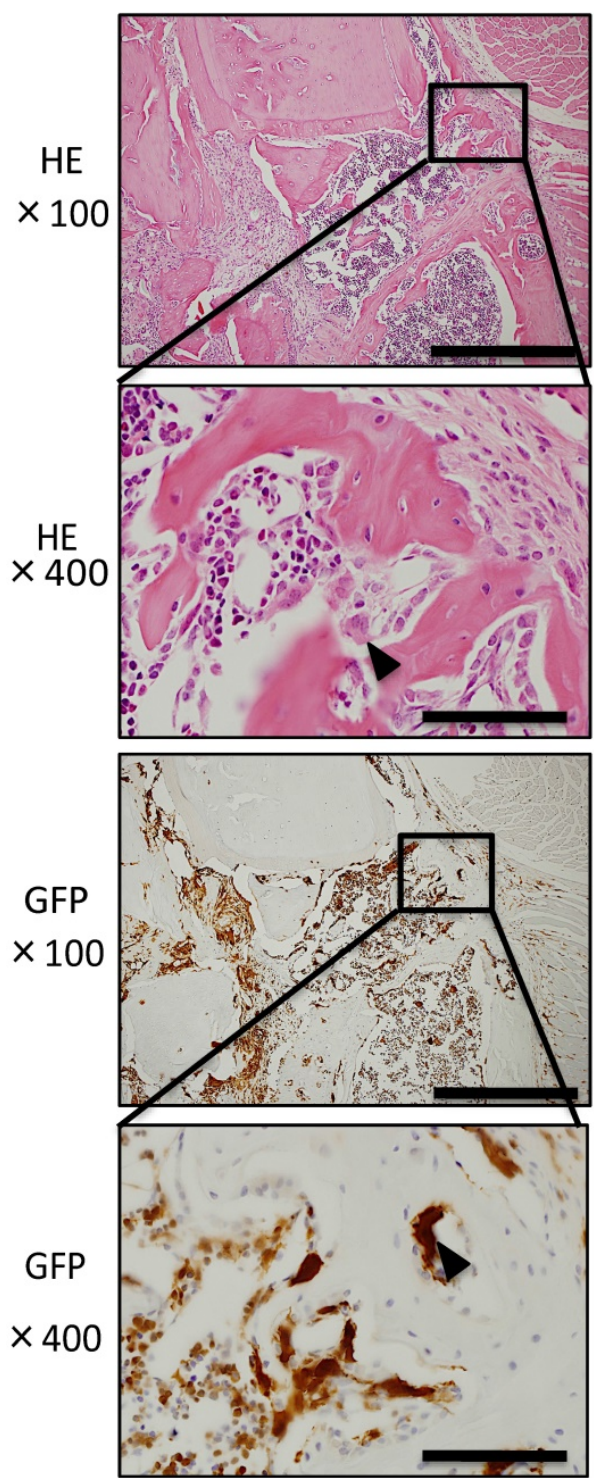

Muscle area
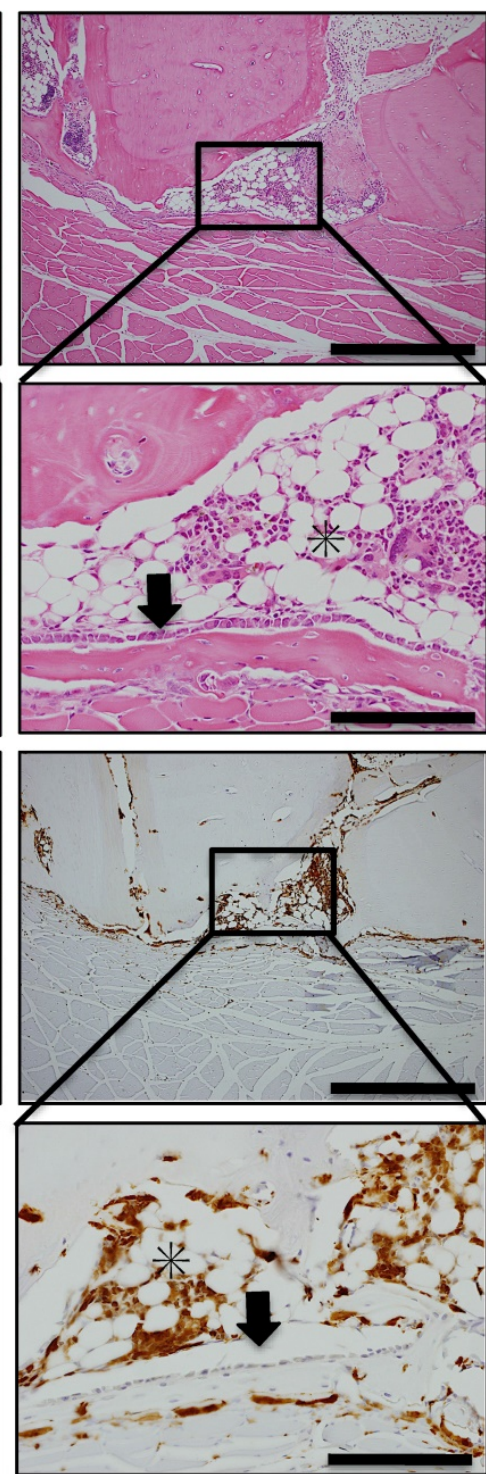

IBM area
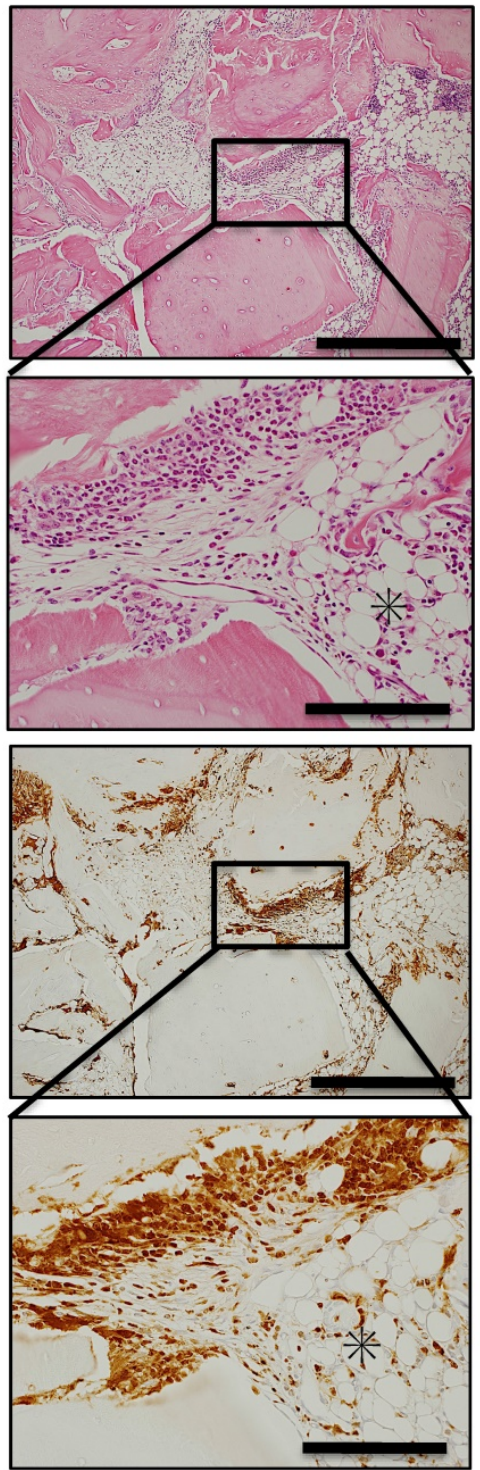

Figure 5. Histological findings at POD 28. Bone marrow-like tissue was observed inside newly formed bone tissue surrounded by osteoblasts (arrowheads) and osteoclast-like cells (arrows). In the IBM area, bone tissue formation was detected around IBM, and bone marrow-like tissue formation (asterisks) occurred with adipocytes and hemocytes present. Blood cells of formed bone marrow-like tissue and osteoclasts-like cells surrounding neonatal bone were GFP-positive, whereas osteoblasts arrayed on the surface of formed bone tissue and osteocytes in neonatal bone were GFP-negative. Scale bars $=200 \mu \mathrm{m}$ in magnification $100 \times$ and scale bars $=50 \mu \mathrm{m}$ in magnification $400 \times$.

At POD 7, neonatal hard tissues consisting of cartilage or bone had already largely formed around the existing bone, and cartilage formation was slightly observed around the existing muscle. At POD 14, neonatal cartilage replaced bone tissue around the existing muscle and bone formation activity was high. Up to POD 28, hard tissue area formation around the existing femur was greater than that in other sites, and significant hard tissue formation was already surrounding the existing femur at the initial stage after IBM implantation as compared with the other sites. Hard tissue formation increased over time in all sites, starting in the area around the existing femur, then the muscle, and lastly the central part of IBM.
The area of hard tissue formation up to POD 28 was the largest around the existing femur, followed by the muscle and the center of IBM (Fig. 7B).

\section{Discussion}

\section{Origin of Cells Involved in Bone Formation}

In $\mathrm{G} \rightarrow \mathrm{W}$ mice, GFP-positive cells were observed in hematopoietic cells constituting bone marrow tissue after bone marrow transplantation. This result indicates that hematopoietic cells were replaced by donor-derived bone marrow cells, and hematopoietic cell reconstruction by bone marrow transplantation was observed. Further, hemocytes and osteoclasts 
were GFP-positive, whereas osteoblasts and chondrocytes were GFP-negative. Therefore, hemocytes and osteoclasts are derived from transplanted bone marrow-derived cells, and osteoblasts and chondrocytes are derived from recipient tissue.

From the results of double-fluorescent IHC for GFP-OC, it was impossible to confirm differentiation of bone marrow-derived cells into osteoblasts after bone marrow transplantation. We speculated that donor hematopoietic stem cells had engrafted in the recipient because hematopoietic reconstitution occurred by bone marrow transplantation. However, GFP-positive osteoblasts and bone cells were not observed, suggesting that engrafted donor hematopoietic stem cells did not differentiate into osteoblasts. This result differs from a previous study that suggested implanted bone marrow cells differentiate into osteoblasts ${ }^{15}$. However, these reports not only showed the possibility that hematopoietic stem cells do not differentiate but also that bone marrow-derived cells fuse to recipient tissue cells 16,17. In recent years, several papers have denied the plasticity of bone marrow stem cells ${ }^{18,19}$. However, the bone marrow includes hematopoietic stem cells, mesenchymal stem cells, and somatic pluripotent progenitor cells, and mesenchymal stem cells only comprise $0.001-0.01 \%$ of cells in the bone marrow. Thus, it is possible that mesenchymal stem cells failed to engraft following bone marrow transplantation in this study.

Stem cells that contain the ability to differentiate into osteoblasts exist in the muscle or subcutaneous connective tissue. Patricia et al. reported that cells from subcutaneous adipose tissue differentiated into adipocytes, osteoblasts, chondrocytes, and muscle in vitro ${ }^{20}$. In addition, Arai et al. reported activated leukocyte cell adhesion molecule-positive cells around the periosteum differentiated into osteoblasts, chondrocytes, and adipocytes ${ }^{21}$. It has also been suggested that mesenchymal stem cells in muscle tissue are involved in fracture healing and ectopic bone formation $22-24$. Moreover, inflammatory cytokines secreted from BMDCs in non-physiological environments such as fractures can promote mesenchymal stem cells to migrate and differentiate into osteoblasts ${ }^{25,26}$. As mentioned above, few reports demonstrated that mesenchymal stem cells are present in tissues and organs, except for bone marrow, and recruited to differentiate into osteoblasts. In this study, bone marrow-derived cells did not directly differentiate into osteoblasts. Therefore, our results indicated that stem cells around the femur and muscle had differentiated into osteoblasts.
A
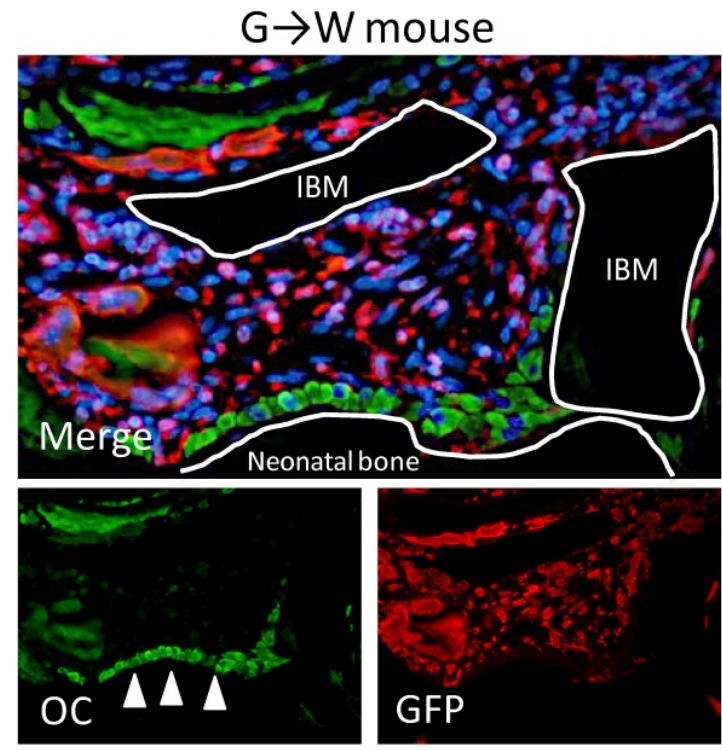

B

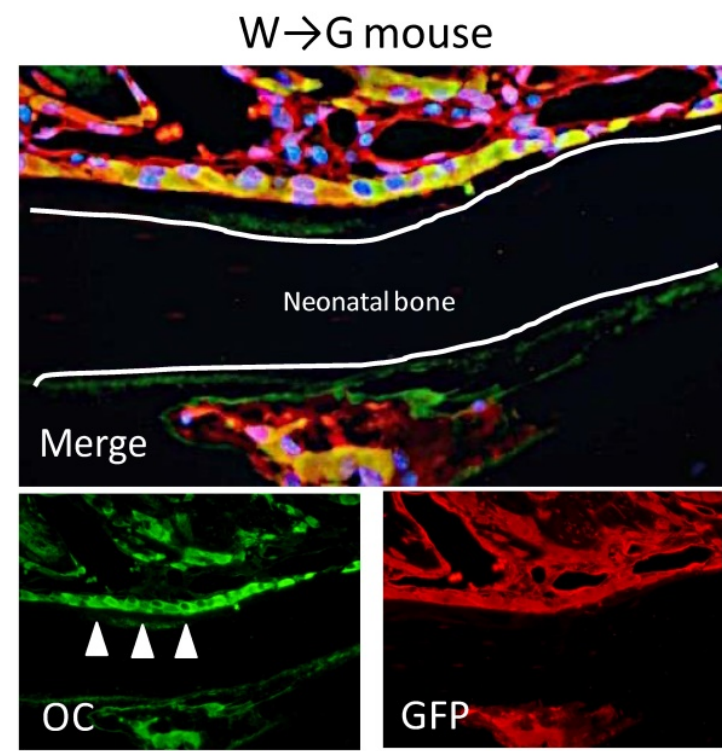

Figure 6. Double-fluorescent IHC at POD 14. (A) In $\mathrm{G} \rightarrow \mathrm{W}$ mice, double-fluorescent IHC for GFP-OC demonstrated that osteoblasts (arrows) in neonatal bone were OC-positive and spindle-shaped or round-shaped cells were GFP-positive. (B) In G $\rightarrow$ W mice, double-fluorescent IHC for GFP-OC demonstrated that osteoblasts (arrows) in neonatal bone and bone matrix were OC-positive and most cells were GFP-OC double-positive (B).

\section{Dynamics and Role of Bone Marrow-Derived Cells Recruited During Bone Formation}

To investigate the role of bone marrow-derived cells in ectopic bone formation, we analyzed localization of GFP-positive cells surrounding IBM and counted the number of GFP-positive cells over time. GFP-positive cells were not present in neonatal hard tissue. However, GFP-positive spindle-shaped and round-shaped cells were observed in granulation-like tissue around formed hard tissue. 
This granulation-like tissue predominantly arose from the surrounding femur and adjacent to muscle tissue before hard tissue formation. The number of GFP-positive cells around the femur and muscle decreased over time, whereas the number of GFP-positive cells in the central part of IBM increased over time. The area of formed hard tissue tended to increase with time regardless of location, particularly in regions with greater numbers of GFP-positive cells such as around the femur and muscle. Moreover, hard tissue formation was observed at POD 7 during the early stage of bone marrow transplantation. That is, bone marrow-derived GFP-positive cells migrated from around the femur and muscle, and the number of GFP-positive cells peaked before neonatal bone formed. Once cartilage and bone tissue formed, the number of GFP-positive cells decreased.

Thus, our results suggested that bone marrowderived cells are involved in ectopic bone formation because the number of migrating GFP-positive cells correlated with the area of formed hard tissue. In

\section{A}

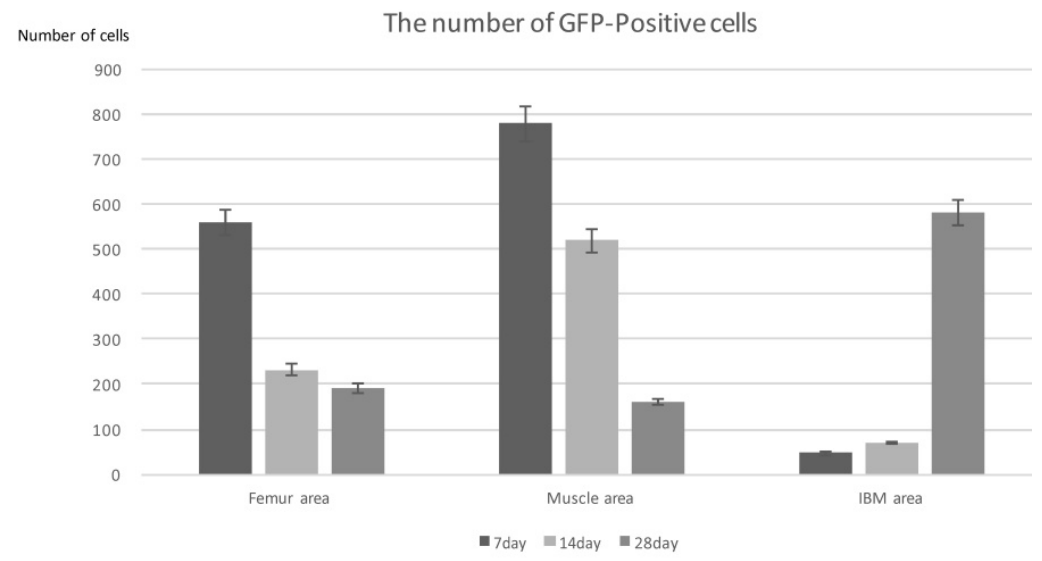

B

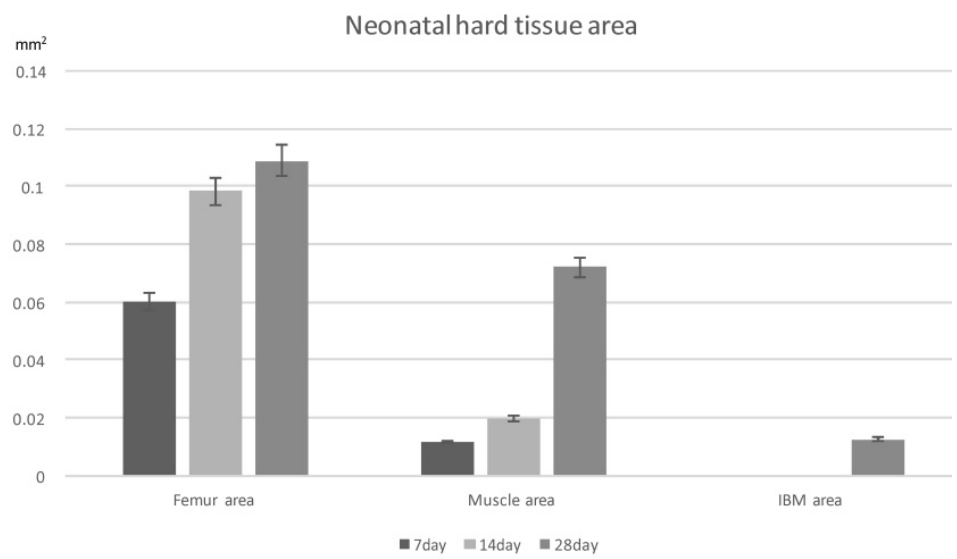

Figure 7. Quantitative analysis. (A) Quantification of the number of GFP-positive cells at the three IBM sites over time. (B) Quantification of the neonatal hard tissue area at the three IBM sites over time. $\mathrm{N}=4$ addition, since GFP-positive cells did not differentiate into osteoblasts, as described above, we considered that bone marrow-derived cells contributed to microenvironment formation for hard tissue formation. Namely, bone marrow-derived cells did not contribute to osteogenesis by differentiating into osteoblasts but contributed to microenvironment formation for ectopic bone formation by promoting stem cell migration in existing tissue. There are some reports that bone marrow-derived cells are recruited at the tissue repair stage by factors released by infiltrating inflammatory cells at the time of tissue injury 27,28 . Our findings support these studies and suggest that bone marrow-derived cells are involved in the accumulation of recipient stem cells during ectopic bone formation.

Other groups have reported that tissue stem cells are well distributed throughout the muscle ${ }^{29}$, and mesenchymal stem cells circulate through the peripheral blood 30,31 . Further, it was reported that some cells adjacent to the periosteum can differentiate into osteoblasts ${ }^{32}$. Our findings that migration of bone marrow-derived cell migration begins early and mostly around the femur and muscle support the results of these reports. The femur is close to the periosteum, which contains cells that can differentiate into osteoblasts, and there are abundant tissue stem cells around the muscle. Conversely, in the central part of IBM, the accumulation of bone marrowderived cells began slowly and in small numbers because the distribution of blood vessels is poor and few tissue stem cells exist around IBM. Thus, bone marrowderived cells contribute to microenvironment formation for osteogenesis, suggesting that the localization and number of bone marrow-derived cells may be the rate-determining condition of microenvironment formation during bone formation.

In conclusion, our findings indicated that the main role of bone marrowderived cells in ectopic osteogenesis is not to contribute to direct bone regeneration by differentiation into osteoblasts, but rather to contribute to microenvironment formation for ectopic osteogenesis such as tissue stem cells that differentiate into osteoblasts.

\section{Acknowledgements}

This study was funded by the Japan Society for Promotion of Science (JSPS) KAKENHI Grants-in-Aid for Science 
Research (Nos.16K20577, 16K11441, 17K11862 and 16K11817).

\section{Competing Interests}

The authors have declared that no competing interest exists.

\section{References}

1. Krause DS, Theise ND, Collector MI, Henegariu O, Hwang S, Gardner R, Neutzel S, Sharkis S. Multi-organ, multi-lineage engraftment by a single bone marrow-derived stem cell. Cell. 2001; 105: 369-77.

2. Tsujigiwa H, Nishizaki K, Teshima T, Takeda Y, Yoshinobu J, Takeuchi A, Orita Y, Sugata Y, Nagatsuka H, Nagai N. The engraftment of transplanted bone marrow-derived cells into the olfactory epithelium. Brain Res. 2005; 1052: 10-15.

3. Einhorn TA. The cell and molecular biology of fracture healing. Clin Orthop Relat Res. 1998; 355: 7-21.

4. Gerstenfeld LC, Cullinane DM, Barnes GL, Graves DT, Einhorn TA. Fracture healing as a post-natal developmental process: molecular, spatial, and temporal aspects of its regulation. J Cell Biochem. 2003; 88: 873-84.

5. Friedenstein AJ, Gorskaja JF, Kulagina NN. Fibroblast precursors in normal and irradiated mouse hematopoietic organs. Exp Hematol. 1976; 4: 267-274.

6. Jiang $\mathrm{Y}$, Jahagirdar $\mathrm{BN}$, Reinhardt RL, Schwartz RE, Keene $\mathrm{CD}$, Ortiz-Gonzalez XR, Reyes M, Lenvik T, Lund T, Blackstad M, Du J, Aldrich S, Lisberg A, Low WC, Largaespada DA, Verfaillie CM. Pluripotency of mesenchymal stem cells derived from adult marrow. Nature. 2002; 447: 879-880.

7. Ohgushi H, Caplan AI. Stem cell technology and bioceramics: from cell to gene engineering. J Biomed Mater Res. 1999; 48: 913-927.

8. Pittenger MF, Mackay AM, Beck SC, Jaiswal RK, Douglas R, Mosca JD, Moorman MA, Simonetti DW, Craig S, Marshak DR. Multilineage potential of adult human mesenchymal stem cells. Science. 1999; 284: 143-147.

9. Caplan AI. Mesenchymal stem cells. J. Orthop. Res. 1991; 9: 641-650

10. Ohgushi H, Dohi Y, Katuda T, Tamai S, Tabata S, Suwa Y. In vitro bone formation by rat marrow cell culture. J Biomed Mater Res. 1996; 32: 333-340.

11. Kihara T, Oshima A, Hirose M, Ohgushi H. Threedimensional visualization analysis of in vitro cultured bone fabricated by rat marrow mesenchymal stem cells. Biochem Biophys Res Commun. 2004; 316: 943-948.

12. Tsujigiwa H, Hirata Y, Katase N, Buery RR, Tamamura R, Ito S, Takagi S, Iida S, Nagatsuka H. The Role of Bone Marrow-Derived Cells During the Bone Healing Process in the GFP Mouse Bone Marrow Transplantation Model. Calcif Tissue Int. 2013; 92: 296-306.

13. Sampath TK, Reddi AH. Dissociative extraction and reconstitution of extracellular matrix components in local bone differentiation. Proc Natl Acad Sci. 1981; 78: 7599-7603.

14. Takita H, Vehof JWM, Jansen JA, Yamamoto M, Tabata Y, Tamura M, Kuboki Y. Carrier dependent cell differentiation of bone morphogenetic protein-2 induced osteogenesis and chondrogenesis during the early implantation stage in rats. J Biomed Mater Res PartA. 2004; 71(11A): 181-189.

15. Dominici M, Marino R, Rasini V, Spano C, Paolucci P, Conte P, Hofmann TJ, Horwitz EM. Donor cell-derived osteopoiesis originates from a self-renewing stem cell with a limited regenerative contribution after transplantation. Blood. 2008; 111: 4386-4391.

16. Terada N, Hamazaki T, Oka M, Hoki M, Mastalerz DM, Nakano Y, Meyer EM, Morel L, Petersen BE, Scott EW. Bone marrow cells adopt the phenotype of other cells by spontaneous cell fusion. Nature. 2002; 416: 542-545.

17. Ying QL, Nichols J, Evans EP, Smith AG. Changing potency by spontaneous fusion. Nature. 2002; 416: 545-548.

18. Nygren JM, Jovinge S, Breitbach M, Säwén P, Röll W, Hescheler J, Taneera J, Fleischmann BK, Jacobsen SE. Bone marrow-derived hematopoietic cells generate cardiomyocytes at a low frequency through cell fusion, but not transdifferentiation. Nat Med. 2004; 10: 494-501.

19. Ebihara Y, Masuya M, Owens R, et al. Hematopoietic origin of fibroblasts and their precursors. Blood. 2004; 104: 193a.

20. Patricia AZ. The Adipose-derived Stem Cells: Looking Back and Looking Ahead. Tissue Engineer. 2002; 7: 211-228

21. Arai F, Ohneda O, Miyamoto T, Zhang XQ, Suda T. Mesenchymal stem cells in perichondrium express activated leukocyte cell adhesion molecule and participate in bone marrow formation. J Exp. Med. 2002; 195: 1549-63.

22. Asakura A, Komaki M, Rudnicki M. Muscle satellite cells are multipotential stem cells that exhibit myogenic, osteogenic, and adipogenic differentiation. Differentiation. 2001; 68: 245-253.

23. Deasy BM, Li Y, Huard J. Tissue engineering with muscle-derived stem cells. Curr Opin Biotechnol. 2004; 15: 419-423

24. Jankowski RJ, Huard J. Myogenic cellular transplantation and regeneration: sorting through progenitor heterogeneity. Panminerva Med. 2004; 46: 81-91.

25. Lemos DR, Eisner C, Hopkins CI, Rossi FM. Skeletal muscle-resident MSCs and bone formation. Bone. 2015; 80: 19-23.
26. Ono $\mathrm{T}$, Okamoto $\mathrm{K}$, Nakashima $\mathrm{T}$, Nitta $\mathrm{T}$, Hori $\mathrm{S}$, Iwakura $\mathrm{Y}$, Takayanagi $\mathrm{H}$. IL-17-producing $\gamma \delta \mathrm{T}$ cells enhance bone regeneration. Nat Commun. 2016; 11(7): 10928.

27. Altschul SF, Madden TL, Schäffer AA, Zhang J, Zhang Z, Miller W, Lipman DJ. Gapped BLAST and PSI-BLAST: a new generation of protein database search programs. Nucleic Acids Res. 1997; 25: 3389-3402.

28. Altschul SF, Gish W. Local alignment statistics. Methods Enzymol. 1996; 266: 460-480.

29. Troy A, Cadwallader AB, Fedorov Y, Tyner K, Tanaka KK, Olwin BB. Coordination of satellite cell activation and self-renewal by Par-complex-dependent asymmetric activation of p38 $\alpha / \beta$ MAPK. Cell Stem Cell. 2012; 11: 541-553.

30. Ferrari G, Cusella AG, Coletta M, Paolucci E, Stornaiuolo A, Cossu G, Mavilio F. Muscle regeneration by bone marrow-derived myogenic progenitors. Science. 1998; 279: 1528-1530.

31. Kuznetsov SA, Mankani MH, Gronthos S, Satomura K, Bianco P, Robey PG. Circulating skeletal stem cells. J Cell Biol. 2001; 153: 1133-1140.

32. Arnsdorf EJ, Jones LM, Carter DR, Jacobs CR. he periosteum as a cellular source for functional tissue engineering. Tissue Eng Part A. 2009; 15: 2637. 